\title{
Study of fragile capillary-porous coatings in power installations
}

\author{
Alexander Genbach ${ }^{1}$, Nellya Jamankulova, ${ }^{1, *}$, Iliya Iliev $^{2}$, and Angel Terziev ${ }^{2}$ \\ ${ }^{1}$ Almaty University of Power Engineering \& Telecommunications, Almaty, Republic of Kazakhstan \\ ${ }^{2}$ Ruse University, Ruse, Bulgaria
}

\begin{abstract}
For carrying out the high-technological processes in heat power installations the fragile capillary-porous coatings up to a limiting condition of heat exchange surface were researched. The coatings made of metallic materials (copper and stainless steel) and of natural mineral media (quartz, granite and teschenit) were studied. A model of the nucleation of steam bubbles in the cells of the porous coatings was developed during vaporization of coolant from their explosive emergence, taking into account the development of the "dry" spots before the damage; also the dynamic angle was defined in the range of $(74 \div 80)$ degrees. The limiting state of the medium according to the model of the bubbles is studied when solving the problem of thermal elasticity. During the destruction of the coating caused by only a compression a number of curves corresponding to a definite thickness of the coming-off coating particle were obtained. Intervals of the specific heat fluxes coming to steam bubbles are established. In these intervals there is a destruction of a porous coating and metal surfaces at the joint action of capillary and gravity potentials.
\end{abstract}

\section{Introduction}

Carrying out high-heat-stressed processes is bound to emergence of the limiting state (before the damage) of the heated surface. In one case, the targeted destruction of material is made, for example, by means of flame-jet burners of rocket type [1,2] from nozzles of which supersonic high-temperature streams expire, and in the other, it requires a cooling system of the nozzles themselves and the combustion chambers in order to avoid burnout and damage of steam generating surface covered with a porous structure [3-17].

As a consequence of operating conditions or specifics in production process, many engineering applications also require consideration of thermo-mechanical problems. The affected structures range from relatively small ones, such as fiber feedthroughs [18] to large dimension structures as bearings [19] or rail-wheels [20].

Based on the above it is of interest to study the capillary-porous structure, produced of natural materials. Such surfaces are being used in large-scale production of power installations (labyrinth seals, gas turbine blades) $[4,7,9]$. Investigation of the limiting condition of metallic wall and its capillary-porous covering is also important. The limiting condition of structure can be studied by solution of thermal elasticity problem.

In some papers the decisive role is assigned to the thermal tensile stresses, because the value of the compression strength of the structure is much higher of tensile strength, and this value is higher in several times in the metallic wall of energy equipment of power installations.

It is well known that the tensile stresses produce cracking of the structure, and they are not decisive for the thermal destruction and major breaking stresses are the shear stresses. Increasing the temperature of the coating for a very short period of time the resulting in a strong dynamic effect. These effects become very significant and the compressive stresses reach their high values, often in several times higher than the compression strength of the material. Therefore, it is necessary to consider these stresses when studying the mechanism of thermal damage of porous coatings. It is necessary to establish the type of stresses more quickly reaching their limits for the supplied heat fluxes.

\section{Model of nucleation of vapor bubbles}

A model of the nucleation of steam bubbles in the cells of capillary-porous structure (Fig. 1) is developed.

The parameters of the figure 1 are as follow: $\mathrm{P}_{\mathrm{s}}, \mathrm{P}_{\mathrm{v}}-$ saturation and vapor pressure in the bubble; $\Delta \mathrm{P}_{\mathrm{g}+\text { cap }}-$ operating pressure generated by gravity and capillary forces; $\mathrm{q}$ - the thermal load; $\mathrm{r}, \mathrm{R}_{\mathrm{cr}}$ - the coordinate and critical radius; $F_{\text {liq }}, F_{w}$ - the contact surface between the liquid and the wall; $\theta$ - dynamical contact wetting angle; $V_{s e g}^{u p}, V_{s \theta g}^{\text {low }}$ - volume segment of the upper and lower part of the bubble.

\footnotetext{
*Corresponding author: dnellya@mail.ru
} 


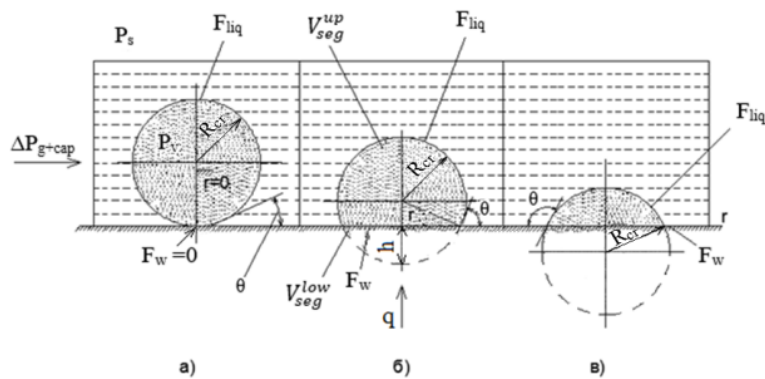

Fig.1. Type of the nucleation of vapor bubble on the steamgenerating surface in the cells of the porous structure:

a) The birth explosion of a steam germ $\left(\mathrm{t}=10^{-8} \div 10^{-6} \mathrm{~s}\right)$;

б) "viable" steam germ having "dry" spot at the base

$\left(\mathrm{t}=10^{-2} \div 1 \mathrm{~s}\right)$;

B) "dying" steam germ of $(\mathrm{t}=1 \div 10 \mathrm{~s})$.

The cubic equation relevant in terms of Figure 1 [1] can be presented with the following:

$$
\cos ^{3} \theta-3 \cos ^{2} \theta-3 \cos \theta+c=0
$$

where $c=1+8\left(R_{c r} / R\right)^{2}, \quad R-$ the current radius of the bubble.

The cubic equation (1) by the Cardano formula further reduced gives the following solution:

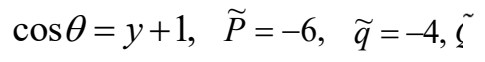

with the following assumptions temperature difference $\Delta T=\Delta T_{\max }, c=c_{\min }=1, \widetilde{\mathrm{P}}, \widetilde{\mathrm{Q}}-$ the terms of equation.

Since $\widetilde{Q}<0$, a trigonometric solution is accepted:

$$
y=-2 \sqrt{-\tilde{i}} \quad, \quad 3 \cdot
$$

where $\cos \tilde{\alpha}=\widetilde{q} / 2 \sqrt{-(\widetilde{P} / 3)^{3}}=0,707, \quad \tilde{\alpha}=45$ degrees.

Then $\mathrm{y}=-0,73$ and the angle $\theta=74^{\circ} 18^{\prime}$.

A similar procedure at the $\Delta T=\Delta T_{\min }$ gives the angle $\theta=75^{\circ} 42^{\prime}$.

The values of $\theta_{i}$ are slightly different from the average value of $\widetilde{\theta}$ adopted in the model of micro-layer growth of the steam bubble $\left(\widetilde{\theta}=80^{\circ}\right)$, which apparently can be explained by neglecting of the bubble shape.

\section{Mathematical model and the research method}

To determine the limit state of two-phase medium according to the model (Fig.1) it is considered the solution of thermal elasticity problem for natural capillary-porous structure (rock) material type and the steam-generating metallic surface.

For a thermal damage of a porous surface and metal wall will be estimated the influence of specific heat flux $q$ supplied to the surface $\mathrm{F}_{\mathrm{w}}$ and the time of exposure $t$ to generate the destructive stresses, granulometric composition of the husk $\left(\delta_{i}\right)$ for the structure and the penetration depth of temperature indignation $(h)$ for metal (Fig.1).

In some papers the decisive role is assigned to the thermal tensile stresses, because the value of the compression strength of the structure in 10 different times is higher of tensile strength, and this value is higher in several times in the metal wall.

It is considered that the tensile stresses only cause a cracking of the structure and they will not be decisive for the thermal damage and major breaking stresses are the shear stresses.

However, when the coating temperature increases in a very short time the dynamic effects become very considerable; the compressive stresses reach its high values, often in several times higher than the compression strength of the material. Therefore, it is necessary to take into account these stresses in the mechanism of thermal damage of porous coatings. It is necessary to find out what kind of stresses more quickly reaches its limits for supplied heat fluxes.

We consider a plate, free in all its sides, and with thickness of $2 \mathrm{~h}$. To the surface of $z=+h$, since the moment of $t=0$, a constant specific heat flux of $q=c$ is introduced. The bottom surface and lateral edges of a plate are considered as adiabatic [2]. We consider that the heat flux q enters the steam bubble through the liquid micro layer, located at the base of the bubble at an angle $\theta$, and through the "dry" spot with radius $r$.

The heat conductivity equation with boundary and initial conditions may be written as follows:

$$
\begin{gathered}
a_{w} \frac{\partial^{2} T}{\partial z^{2}}=\frac{\partial T}{\partial t} \\
T=0, \quad t<0, \\
\lambda_{w} \frac{\partial T}{\partial z}=q \quad z=+h, \\
\lambda_{w} \frac{\partial T}{\partial z}=0 \quad z=-h,
\end{gathered}
$$

where $a_{w}-$ thermal diffusivity coefficient of the material; $\lambda_{w}-$ thermal conductivity coefficient of the material.

Temperature distribution on plate thickness depends on the thermal-physical properties of a material, the value of a heat flux and the time of its appearance:

$$
T\left(\frac{z}{h} ; t\right)=q\left\{\begin{array}{l}
\frac{\mu}{2(c \rho \lambda)_{W}} t+\frac{3 z^{2} / h^{2}+6 z / h-1}{12 \mu}-\frac{4}{\pi^{2} \mu} \times \\
\times \sum_{n=1}^{\infty} \frac{(-1)^{n}}{n^{2}} \exp \left[-(n \pi \mu)^{2} t / 4(c \rho \lambda)_{W}\right] \cos \left[\frac{n \pi}{2}\left(\frac{z}{h}+1\right)\right]
\end{array}\right\}
$$

where $c_{\mathrm{w}}-$ heat capacity of the material; $\rho_{\mathrm{w}}-$ density of the material; $\mathrm{n}$ - positive integers; $\mu=\lambda_{w} / \mathrm{h}-$ parameter, may considered as conditional heat conduction parameter.

In case the temperature distribution in a plate is known, it is possible to calculate the thermal stress of stretching and the compression, appearing at some moment $t$ at various depth from a surface $\delta_{i}=\left(h-z_{i}\right)$ at the given value of a heat flux of $q=c$.

The tensile state of the plate is clear at a variable plate temperature by thickness. The tension $\sigma$ is defined with accordance to the following equation: 


$$
\sigma_{x x}=\sigma_{y y}=-\frac{\alpha \times E}{1-v} T\left(\frac{z}{h} ; t\right)+\frac{1}{(1-v) 2 h} \int_{-h}^{+h} \alpha E T\left(\frac{z}{h} ; t\right) d z
$$

where the first term is part of the compressive stress and the second term is stretching component; $\alpha$ - coefficient of linear expansion; E - Jung's module; $v-$ the coefficient of lateral contraction.

The product $(\alpha \times \mathrm{E})$ doesn't depend on temperature; therefore the expression for tension of stretching is simplified.

Assuming the limiting values for compressive stresses and stretching for each of the rocks and metal coating, a functional relation of the heat flux $q_{i}$ caused the damage is obtained for the time and penetration depth. When the plate surface temperature is equal to temperature of melting for both coating and the metal, the values of the specific heat fluxes, necessary for the melting of the top layer during different operating modes are determined.

Thus, for each case the relations of a heat flux in terms of time influencing the surface are:

- melting of a plate surface at a temperature $T_{m}$

$$
q_{1}=T_{m} /\left\{\begin{array}{l}
\frac{\mu}{2(c \rho \lambda)_{W}} t+\frac{2}{3 \mu}-\frac{4}{\pi^{2} \mu} \times \\
\times \sum_{n=1}^{\infty} \frac{(-1)^{n}}{n^{2}} \exp \left[-(n \pi \mu)^{2} t / 4(c \rho \lambda)_{W}\right] \cos n \pi
\end{array}\right\}
$$

- production of limiting compressive stresses $\sigma_{\text {comp }}$

$$
q_{2}=\frac{(1-v) \sigma_{\text {omp }}}{\alpha E}\left\{\begin{array}{l}
\frac{\mu}{2(c \rho \lambda)_{W}} t+\frac{3 z^{2} / h^{2}+6 z / h-1}{12 \mu}-\frac{4}{\pi^{2} \mu} \times \\
\times \sum_{n=1}^{\infty} \frac{(-1)^{n}}{n^{2}} \exp \left[-(n \pi \mu)^{2} t / 4(c \rho \lambda)_{W}\right] \times \\
\left.\frac{n \pi}{2}\left(\frac{z}{h}+1\right)\right]
\end{array}\right\}
$$

- production of limiting tensile stresses $\sigma_{\text {str }}$

$$
q_{3}=\frac{(1-v) \sigma_{s t r}}{\alpha E} / \frac{\mu}{2(c \rho \lambda)_{W}} t
$$

\section{The research results}

For the plates made of quartz, granite, teshenit and metallic coatings, the functional relations for $q_{1}, q_{2}, q_{3}$ in terms of time for fixed values of the particle size of coatings, or a penetration depth of temperature indignation for metal are calculated. Thermal mechanical characteristics of rock and metals are presented in table 1.

Results from calculations are shown on fig. 2 and fig. 3 . In case of a porous quartz plate, heat fluxes are calculated for extended time interval $\left(10^{-8} \div 10^{3}\right) \mathrm{s}$. The lower interval value $\left(10^{-8} \mathrm{~s}\right)$ is the relaxation time when the birth explosion of a steam germ has taken place.

Table 1. Thermo-mechanical properties of the tested materials.

\begin{tabular}{|c|c|c|c|c|c|}
\hline Materia & Qua & Gra & Teshe & $\begin{array}{c}\text { Cop } \\
\text { per }\end{array}$ & $\begin{array}{c}\text { Stain } \\
\text { nit }\end{array}$ \\
$\begin{array}{c}\text { rtz } \\
\text { nite }\end{array}$ & $\begin{array}{c}\mathrm{Cu}+ \\
\text { less } \\
\end{array}$ & & & 0,56 & steel \\
\hline
\end{tabular}

\begin{tabular}{|c|c|c|c|c|c|}
\hline $\begin{array}{c}\rho, \\
\mathrm{kg} / \mathrm{m}^{3} \\
\times 10^{3}\end{array}$ & 2,6 & 2,58 & 2,7 & 8,9 & 7,8 \\
\hline $\begin{array}{c}\alpha, \\
1 / K \\
\times 10^{-5}\end{array}$ & $\begin{array}{c}1,5 \\
6\end{array}$ & 1,16 & 5,44 & 1,6 & 1,1 \\
\hline $\begin{array}{c}C, \mathrm{~J} / \\
\mathrm{kg} \cdot \mathrm{K}\end{array}$ & 117 & 921 & 937 & 390 & 516 \\
\hline $\begin{array}{c}\lambda, W / \\
m \cdot K\end{array}$ & 10, & 3,15 & 1,44 & 390 & 16 \\
\hline $\begin{array}{c}T_{m,} \\
{ }^{\circ} \mathrm{C}\end{array}$ & $\begin{array}{c}178 \\
8\end{array}$ & 1230 & 1140 & 1100 & 1300 \\
\hline $\begin{array}{c}E, \\
N / m^{2} \\
\times 10^{10}\end{array}$ & 7,3 & 2,8 & 4,97 & 4,97 & 21,6 \\
\hline $\begin{array}{c}\sigma_{\text {str }} \\
N / m^{2} \\
\times 10^{6}\end{array}$ & 3,9 & 20,5 & 7,6 & 220 & 700 \\
\hline $\begin{array}{l}\sigma_{\text {comp }} \\
N / \mathrm{m}^{2} \\
\times 10^{6}\end{array}$ & 78, & 260 & 159 & 1570 & 2500 \\
\hline
\end{tabular}

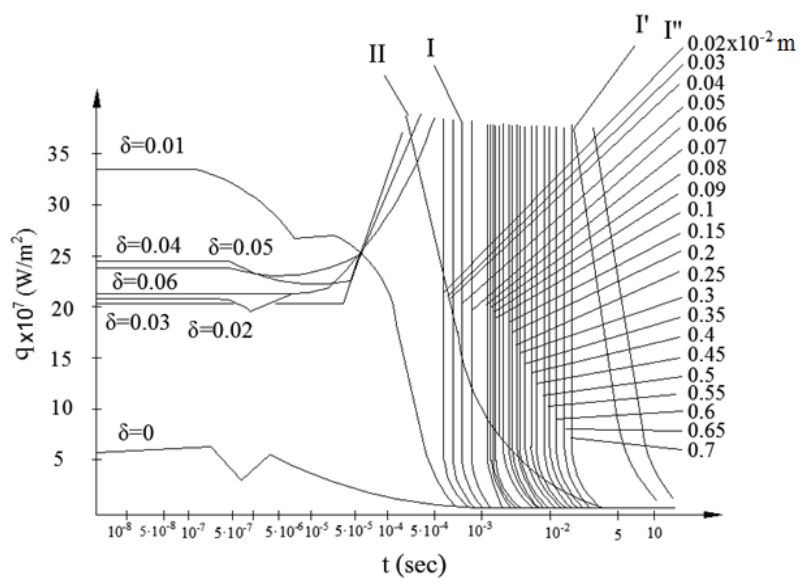

Fig.2. Curves of heat fluxes causing compressive stresses of a quartz coating in terms of action time for various thickness of coming-off particles: I - tensile stresses, sufficient for damage; II - melting of surfaces; I' - copper, $h=0,1 \times 10^{-3} \mathrm{~m}$, I" stainless steel, $h=0,1 \times 10^{-3} \mathrm{~m}$.

It is clear (figure 2 ) that for time interval $\left(10^{-8} \div 10^{-3}\right)$ s equations $q_{1}$ and $q_{2}$, represented by the hyperbolic type curves in coordinates $(q ; t)$, lost its physical sense since in the problem description the heat conductivity equation is assumed as a basis. When considering the micro processes, it is necessary to add the following term $K \frac{\partial^{2} T}{\partial t^{2}}$. As far as a thermal destruction is regarded as a macro process, we accept that it proceeds for the time $\left(5 \cdot 10^{-8} \div 10^{3}\right)$ s. Curves for the heat fluxes $q_{1}, q_{2}, q_{3}$ in terms of time on the plates made from quartz coating is shown in figure 2 .

\section{Discussion of results and analysis}

In case of a coating damage only by compression, a number of curves were obtained as each of them 
corresponds to a certain thickness of a coming-off particle. For each value of heat flux and certain interval of time the particles with a thickness of $\delta_{i}$ are obtained. For the quartz and granite coatings the maximal thickness of the particles coming-off under the action of compression is $(0,25 \div 0,3) \times 10^{-2} \mathrm{~m}$.

To confirm the calculation theory of the equation (4) the experiment was performed (Fig. 3).

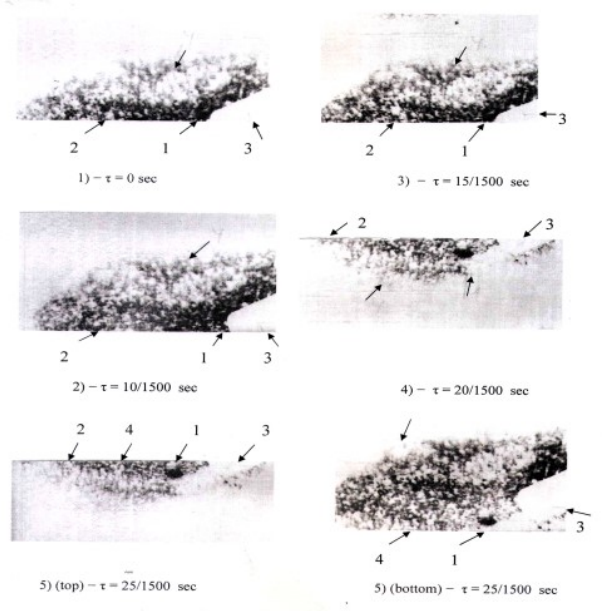

Fig. 3. Filming of husk flight with size $2,5 \times 10^{-3} \mathrm{~m}$ at the damage of teschenit coating when exposed to torch of a rocket burner $\left(\mathrm{q}=1,2 \times 10^{6} \mathrm{~W} / \mathrm{m}^{2} ; \tau=2,2 \mathrm{~s}\right) .1$ - area of cover damage; 2 - flying particles; 3 - nozzle of fiery-jet burner; 4 capillary-porous coating.

Sections of compressive curves defining a separation of the larger particles with thickness of $\delta>0,3 \times 10^{-2} \mathrm{~m}$ for big heat fluxes and short times of action $t$ are shielded by a curve of melting, and in case of small heat fluxes and considerable intervals of time - by a curve of stretching. Moreover, the curve of surface melting of a quartz coating is considerably higher than of a granite one that explains the steady damage of fragile coatings of quartz and quartz-bearing rocks.

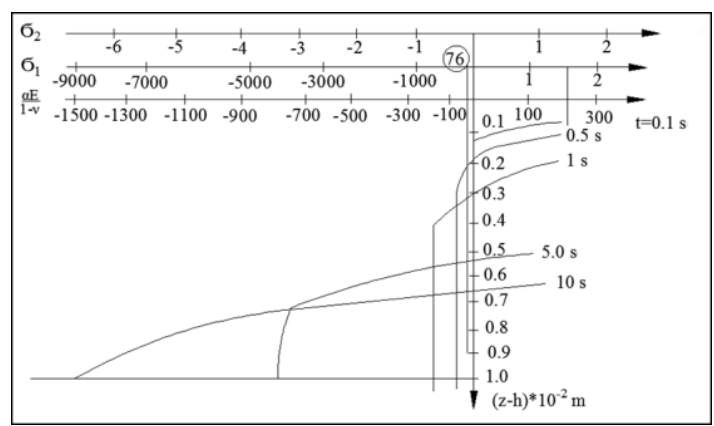

Fig. 4. Diagrams of stresses in thickness for plate with teshenit coating at different $\mathrm{q}$ and $\mathrm{t}: q_{1}=6,6 \cdot 10^{6} \mathrm{~W} / \mathrm{m}^{2} ; q_{2}=1 \cdot 10^{4}$ $\mathrm{W} / \mathrm{m}^{2} ; 76$ - tensile strength; $\sigma, 10^{5} \mathrm{~N} / \mathrm{m}^{2} ; E, 10^{5} \mathrm{~N} / \mathrm{m}^{2}$.

Relationship of compressive and tensile stresses can be seen in Fig. 4, which represents the stress distribution inside the plate of teshenit coating for various time intervals from the beginning of the process. At the time of impact (approximately $t \sim 10^{-1} \mathrm{~s}$ ), there are only compressive stresses. Since $\mathrm{t} \sim 1 \mathrm{~s}$, in a region of $\Delta(h-$ $\left.z_{i}\right)$ to $0,3 \times 10^{-2} \mathrm{~m}$ the compressive stresses become the tensile stresses in a very short period of time as for the different time intervals they are located at different depths from the surface of the plate. In the region of transition from compressive stress to the tensile stress, probably the greatest shear stresses of layers of rock surface will be observed. In time dependence, the shear stresses reach their limit values after destructive compressive stresses and, obviously, before the maximum values of tensile stresses.

When increasing the specific heat flux in a heated layer, and decreasing the heating time, the impact of compressive stresses increases. Despite of the high resistance to compression, the damage of the capillaryporous coating by the compressive thermal stress occurs in more favorable conditions, immediately and in a very small volumes.

The curve of surface melting of a quartz coating is considerably higher, than of a granite one, and even more above than of teschenit, which explains the steady damage of fragile coatings of quartz-bearing structures.

\section{Conclusion}

The damage of natural coatings under the action of compressive forces comes in time much earlier than the tensile forces. Probable damage will occur under the action of compressive and shear forces. Intervals of heat flux are different for coating of quartz $\left(q_{\max }=7 \cdot 10^{7}\right.$ $\left.\mathrm{W} / \mathrm{m}^{2} ; \quad q_{\min }=8 \cdot 10^{4} \mathrm{~W} / \mathrm{m}^{2}\right)$ and granite $\left(q_{\max }=1 \cdot 10^{7}\right.$ $\left.\mathrm{W} / \mathrm{m}^{2} ; q_{\min }=21 \cdot 10^{4} \mathrm{~W} / \mathrm{m}^{2}\right)$ within this damage occurs.

Each values of thickness $\delta_{i}$ of coming-off particles under the influence of compression forces correspond to their limiting values of heat fluxes within to specified ranges.

For uncooled metal surfaces the value of $q_{\min }=1 \cdot 10^{4}$ $\mathrm{W} / \mathrm{m}^{2}$ and in the case of porous cooling system operating at the combined action of capillary and mass forces, the value of $q_{\max }=1 \cdot 10^{6} \mathrm{~W} / \mathrm{m}^{2}$ [6].

The maximal thickness of the particles separated under the action of compression, for coatings of granite, quartz and teschenite is $(0,25 \div 0,3) \times 10^{-2} \mathrm{~m}$.

Time separation of particles from the teshenit coating defined by high-speed filming [2] is less than 0.5 seconds, depending on the supplied heat flux, which is agreed with the data given in Fig. 3 , when $t_{\min } \geq 0,1$ second.

\section{References}

[1] Polyaev V. M., Genbach A.A. The growth rate of steam bubbles in porous structures, News of higher education institutions. Mechanical engineering. № 10, pp. 56-61, (1990)

[2] Polyaev V. M., Genbach A.N., Genbach A.A. A limit condition of a surface at thermal influence, TVT, V. 29, № 5, pp. 923-934, (1991)

[3] Polyaev V.M., Genbach A.A. Control of Heat Transfer in a Porous Cooling System, Second world conference on experimental heat transfer, fluid mechanics and thermodynamics. 1991, Dubrovnik, Yugoslavia, 23-28 June, pp. 639-644, (1991) 
[4] Polyaev V.M., Genbach A.A. Applications of porous system, Proceedings of the universities. Energy, №12, pp. 97-101, (1991)

[5] Polyaev V.M., Genbach A.A. Heat management in porous structures, Bulletin of the Russian Academy of Sciences. Energy and transport, V. 38, №6, pp. 105-110, (1992)

[6] Polyaev V.M., Genbach A.A. Heat transfer in a porous system operating under the joint action of capillary and gravitational forces, Thermal Engineering, V7, pp. 55-58, (1993)

[7] Genbach A.A., Kulbakina N.V. Dust suppression and dust removal with a circulation of foam generator with a porous structure, Energy and Fuel Resources of Kazakhstan, №4, pp. 62-65, (2010)

[8] Polyaev V.M., Genbach A.A. Management of internal characteristics of boiling in porous system, Cryogenic equipment and conditioning: Collection of works of MGTU. Moscow, 1991, pp. 224-237, (1991)

[9] Polyaev V.M., Genbach A.A. Use of porous system in power stations, Power industry, №1, pp. 40-43, (1992)

[10] Polyaev V.M., Genbach A.A. Calculation of thermal streams in the porous cooling system, News of higher education institutions. Aircraft equipment. №2, pp. 71-74, (1992)

[11] Genbach. A.A., Gnatchenko. Y.A. Cooling system of thermal-element-detonation burner. Combustion chambers, diffuser, confuser, Vestnik KazNTU, Almaty, V. 61, №4, July, pp. 87-91, (2007)

[12] Pelevin F.V., Avramov N.I., Orlin S.A., Sincov L.A., The efficiency of heat transfer in porous element of liquid rockets construction, Engineering magazine: Science and Innovation, issue № 4, (2013)

[13] Kravets V. Yu. Boiling Heat-Transfer Intensity on Small-Scale Surface, International Review of Mechanical Engineering, V. 6, № 3, Part A, pp. 479-484, (2012)

[14] Ovsyanik A.V. Modelling of heat-exchange processes at liquids boiling. Gomel State Technical University named after Sukhoy P.O., Gomel, 2012, P. 284, (2012)

[15] Nizovcev M.I., Srerliagov M.N., Terehov V.I., Distribution of thermal limits in the capillary impregnation of porous materials, Polzunovsky Paper, №1, pp. 39-43, (2010)

[16] Patel R.M., Deheri, G.M. Effect of various porous structures on the shliomis model based ferrofluid lubrication of the film squeezed between rotating rough curved plates, Facta Universitatis, Series: Mechanical Engineering V. 12, No 3, pp. $305-$ 323, (2014)

[17] Genbach A.A., Jamankulova N.O., Bakic V.V. The processes of vaporization in the porous structures working with the excess of liquid. Thermal Science, V.21, No 1A, pp. 363 - 373, (2017)

[18] Marinkovic D., Zehn M., Milic P. On the design of thermally loaded fiber optics feedthroughs. Thermal Science, V.20, Suppl. 5, pp. 1313-1320, (2016)
[19] Krstić V., Milčić D., Milčić M. A thermal analysis of the threaded spindle bearing assembly in numerically controlled machine tools. Facta Universitatis - Series Mechanical Engineering, in press, doi: 10.22190/FUME170512022K

[20] Milošević M., Miltenović A., Banić M., Tomić M. Determination of residual stress in the rail wheel during quenching process by FEM simulation. Facta Universitatis - Series Mechanical Engineering, V.15, No. 3, pp. 413-425, (2017) 